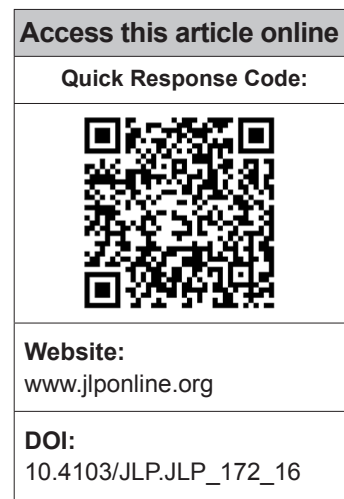

${ }^{1}$ Department of Medical Laboratory Science, School of Basic Medical Sciences, College of Medical Sciences, University of Benin, Benin City, ${ }^{2}$ Federal Medical Center, Owo, Ondo State, Nigeria

Address for correspondence: Dr. Mathias Abiodun Emokpae,

Department of Medical Laboratory Science, School of Basic Medical Sciences, University of Benin, Benin City, Nigeria.

E-mail: mathias.

emokpae@uniben.edu

Submission: 29-12-2016 Accepted: 04-07-2017

\title{
Asymptomatic thyroid dysfunction in human immunodeficiency virus-1-infected subjects
}

\author{
Mathias Abiodun Emokpae', Imwonghomwen Mercy Akinnuoye ${ }^{1,2}$
}

\section{Abstract:}

BACKGROUND: Thyroid hormone abnormalities have been reported elsewhere in human immunodeficiency virus-1 (HIV-1)-infected individuals, but such studies in Nigerians are scarce in literature.

OBJECTIVE: To evaluate thyroid function in HIV-1-infected individuals and to correlate thyroid function parameters with cluster of differentiation $\left(C D 4^{+}\right)$cell count.

MATERIALS AND METHODS: Total thyroxine (T4), total triiodothyronine (T3), thyroid-stimulating hormone (TSH), and CD4+ were estimated in 100 HIV-1-positive individuals on highly active antiretroviral therapy (HAART), 100 HIV-1-positive HAART naïve, and 100 HIV-1-negative controls. The mean values were compared between the groups, and CD4 ${ }^{+}$cell count was correlated with measured thyroid hormones.

RESULTS: Thyroid function abnormalities were seen in $52 \mathrm{HIV}$-1-positive individuals on HAART and 56 individuals without HAART treatment. The pattern of thyroid hormone abnormalities is similar in both groups. Among the individuals on HAART, 10 had subclinical hypothyroid, 42 sick euthyroid, and 48 had normal thyroid hormones levels. Similarly, among those without HAART therapy, seven had subclinical hypothyroid, 49 sick euthyroid, and 44 had normal thyroid hormones levels. The HIV-1-positive individuals had significantly lower $(P<0.001) \mathrm{CD} 4^{+}$cell count, TSH $(P<0.05)$, T3 $(P<0.01)$, and T4 $(P<0.001)$ when compared with controls. On the other hand, HIV-1-positive individuals on HAART had significantly higher $(P<0.01)$ CD4 ${ }^{+}$cell count and lower $(P<0.05)$ T4 levels than the HAART naïve group. CD4 ${ }^{+}$correlated positively with T4 in HIV-1-positive individuals on HAART $(r=0.26 ; P=0.016)$ and HAART naïve $(r=0.218 ; P=0.038)$. There was no significant correlation between $\mathrm{CD}^{+}$and measured thyroid hormones in the control individuals.

CONCLUSION: Asymptomatic thyroid hormone abnormalities are common in HIV-infected individuals, and these abnormalities are independent of whether the individuals were on HAART or without HAART treatment.

Key words:

Cluster of differentiation, human immunodeficiency virus-1, thyroid-stimulating hormone, total thyroxine, triiodothyronine

\section{Introduction}

1 in hyroid dysfunction has been reported in human immunodeficiency virus-1 (HIV-1)-infected individuals, but the pattern of abnormalities varies from place to place, and the effects of highly active antiretroviral drugs (HAART) on thyroid

This is an open access article distributed under the terms of the Creative Commons Attribution-NonCommercial-ShareAlike 3.0 License, which allows others to remix, tweak, and build upon the work non-commercially, as long as the author is credited and the new creations are licensed under the identical terms.

For reprints contact: reprints@medknow.com function have not been widely reported in Nigeria. HIV was described as a disease of greater demographic diversity that affects individuals of all ages, gender, and races, ${ }^{[1]}$ with higher prevalence rate in Africa. In Nigeria, about $3.1 \%$ of the population are living with the infection. ${ }^{[2]} \mathrm{HIV}-1$ infection can involve the endocrine system. Various endocrine dysfunctions involving thyroid, pituitary, gonads, pancreas, and adrenal have

How to cite this article: Emokpae MA, Akinnuoye IM. Asymptomatic thyroid dysfunction in human immunodeficiency virus-1-infected subjects. J Lab Physicians 2018;10:130-4. 
been reported in infected individuals. ${ }^{[3-8]}$ The occurrence of thyroid dysfunction was observed to be about 35\% higher in HIV-1-infected individuals than in the general population. ${ }^{[9,10]}$ Reports of thyroid function abnormalities in Nigerians with HIV-1 infection are scarce in literature. It is not completely understood why thyroid dysfunction is more common in HIV-1-infected individuals than general population, but the susceptibility of infected individuals to thyroid dysfunction may be related to HIV. ${ }^{[3]}$ Studies have suggested that HIV-1 infection could change the course of thyroid disease. ${ }^{[11,12]}$ Asymptomatic and subtle thyroid abnormalities have been reported which include sick euthyroid state, ${ }^{[13]}$ subclinical hypothyroidism, ${ }^{[14,15]}$ hypothyroidism, ${ }^{[16-18]}$ thyroiditis, and Grave's disease. ${ }^{[19]}$ Subclinical hypothyroidism is the most commonly reported thyroid abnormalities in HIV-1 infection in literature, but it is not clear which of the thyroid abnormalities are most common in our setting. In addition, the HAART used in the management of HIV-1 infection is an important factor implicated in thyroid dysfunction. Some authors have reported that HAART could increase the incidence of thyroid abnormalities, especially stavudine which was reported to directly affect the synthesis and secretion of thyroid hormones, ${ }^{[15,20]}$ even though this claim is not generally accepted by some authors. ${ }^{[21]}$ This study was therefore undertaken to evaluate thyroid function in HIV-1-infected Nigerians on HAART and HAART naïve and to correlate thyroid function parameters with cluster of differentiation $\left(\mathrm{CD}^{+}\right)$cell count.

\section{Materials and Methods}

This is a cross-sectional, case-control prospective study of confirmed HIV-1-positive individuals who were randomly recruited from July 2015 to August 2016. The study protocol was reviewed and approved by the Health Research Ethics Committee of the institution with code FMC/OW/380/VOL. XXIX/150 dated July 14,2015 . Informed consent was obtained from the participants. The sample size was determined using sample determination in health studies and a prevalence of $3.6 \% .^{[22]}$

All confirmed HIV-1-positive individuals who had been on HAART treatment for a minimum of 6 months and those newly diagnosed were included in the study. Any individual with chronic renal impairment, liver disease, chronic hepatitis B and C infection, and acute systemic infection likely to affect thyroid function as well as those who declined to give consent were excluded from the study.

A semi-structured questionnaire was used to collect clinical and demographic data from the participants. It includes sociodemographic profile, age, gender, under current illness, blood transfusion, duration of HIV infection, and presence of hepatitis B and C infection. Any clinical feature of thyroid dysfunction was documented. The control group was made up of apparently healthy HIV-1-negative individuals selected from staff and students of the institution.

Five milliliters of blood was collected from the participants, of which $2 \mathrm{~mL}$ was dispensed into ethylenediaminetetraacetic acid container and the remaining $3 \mathrm{~mL}$ was emptied into plain container. The sample in a plain container was allowed to clot for $30 \mathrm{~min}$ at room temperature. This was centrifuged and serum separated into another plain container. The serum was stored at $-20^{\circ} \mathrm{C}$ until analyzed. The $\mathrm{CD}^{+}$was quantitated using CyFlow automated cell counter (Partec, Germany), while total thyroxine (T4), total triiodothyronine (T3), and thyroid-stimulating hormone (TSH) were analyzed by ELISA technique using reagent supplied by Inteco Diagnostics (UK). The lower and upper limits of locally established reference ranges are $\mathrm{TSH}=0.35-5.50 \mu \mathrm{IU} / \mathrm{mL}$; $\mathrm{T} 3=0.6-2.0 \mathrm{ng} / \mathrm{dL}$; and T4=4.5-12.6 $\mathrm{g} / \mathrm{dL}$. The thyroid function abnormalities were defined based on the locally established reference ranges as follows:

- Hyperthyroid - TSH $<0.35 \mu \mathrm{IU} / \mathrm{mL}$ with $\mathrm{T} 4>12.6 \mu \mathrm{IU} / \mathrm{dL}$

- Hypothyroid-TSH $>5.5 \mu \mathrm{IU} / \mathrm{mL}$ with $\mathrm{T} 4<4.5 \mu \mathrm{IU} / \mathrm{dL}$

- Subclinical hypothyroid - TSH >5.5 with normal T3 and T4

- Subclinical hyperthyroid - TSH $<0.35$ with normal T3 and T4

- Sick euthyroid - TSH normal with low T3.

To ensure accurate and precise results, quality control sera were included in the assays. The control sera used were ACUSERA immunoassay premium plus level 1,2, and 3 by RANDOX (Cat No: IA3109, IA3110, and IA3111, respectively).

\section{Statistical analysis}

The data were analyzed using SPSS version 20.0 (Chicago IL, USA). The values were expressed as mean \pm standard deviation. Statistical comparisons were done by Chi-square test, Student's $t$-test, and one-way analysis of variance while the thyroid function test parameters were correlated with $\mathrm{CD} 4^{+}$using Pearson correlation coefficient. A $P<0.05$ was considered statistically significant.

\section{Results}

The results are as presented in Tables 1-5. The study participants were 100 (33 males, 67 females and mean age $39.6 \pm 9.3$ years) HIV-1-positive individuals on HAART, 100 (34 males, 66 females and mean age $38.0 \pm 7.9$ years) HIV-1-positive HAART naïve, and 100 (35 males, 
Table 1: Thyroid function parameters among human immunodeficiency virus-1-positive individualssubjects

\begin{tabular}{lccc}
\hline Measured variables & $\begin{array}{c}\text { HIV-1-positive individuals } \\
\text { subjects on HAART }(\boldsymbol{n}=100)\end{array}$ & $\begin{array}{c}\text { HIV-1-positive individuals } \\
\text { subjects HAART naïve }(\boldsymbol{n}=100)\end{array}$ & $\begin{array}{c}\text { Total number of } \\
\text { individualssubjects }\end{array}$ \\
\hline Age (years) & $39.6 \pm 9.3$ & $38.0 \pm 7.9$ & 67 \\
Number of males & 33 & 34 & 133 \\
Number of females & 67 & 66 & 92 \\
Normal (euthyroid) & 48 & 44 & 17 \\
Sub-clinical hypothyroid & 10 & 7 & 9.068 \\
Sick euthyroid & 42 & 49 & 91 \\
\hline
\end{tabular}

HIV-1 = Human immunodeficiency virus, HAART = Highly active anti-retroviral therapy

Table 2: Comparison of the mean levels of thyroid hormones and cluster of differentiation cell count in human immunodeficiency virus-1-positive individuals on highly active antiretroviral therapy, highly active antiretroviral therapy naïve compared with controls

\begin{tabular}{|c|c|c|c|c|}
\hline $\begin{array}{l}\text { Measured } \\
\text { parameters }\end{array}$ & $\begin{array}{l}\text { HIV-1-positive individuals } \\
\text { on HAART }(n=100)\end{array}$ & $\begin{array}{l}\text { HIV-1-positive individuals } \\
\text { HAART naïve }(n=100)\end{array}$ & $\begin{array}{l}\text { HIV-1 seronegative } \\
\text { individuals }(n=100)\end{array}$ & $P$ \\
\hline $\mathrm{CD}^{+}{ }^{+}$(cells $\left./ \mu \mathrm{L}\right)$ & $480.9 \pm 26.7^{d}$ & $418.4 \pm 29.0^{\mathrm{d}, \mathrm{c}}$ & $850.1 \pm 28.7$ & 0.001 \\
\hline TSH $(\mu \mathrm{IU} / \mathrm{mL})$ & $2.36 \pm 0.15^{b}$ & $2.28 \pm 0.11^{a, b}$ & $3.18 \pm 0.09$ & 0.05 \\
\hline T3 (ng/dL) & $0.62 \pm 0.50^{c}$ & $0.80 \pm 0.41^{c}$ & $1.07 \pm 0.51$ & 0.01 \\
\hline $\mathrm{T} 4$ ( $\mu \mathrm{g} / \mathrm{dL})$ & $3.06 \pm 0.15^{b, d}$ & $3.41 \pm 0.14^{d}$ & $4.85 \pm 0.29$ & 0.001 \\
\hline
\end{tabular}

Table 3: Correlation between cluster of differentiation cell count and thyroid hormone levels in human immunodeficiency virus-positive individuals on highly active antiretroviral therapy

\begin{tabular}{lcc}
\hline Measured variables & $\boldsymbol{R}$ & $\boldsymbol{P}$ \\
\hline $\mathrm{CD} 4^{+}$and T3 & 0.15 & 0.153 \\
$\mathrm{CD} 4^{+}$and T4 & 0.26 & 0.016 \\
$\mathrm{CD} 4^{+}$and TSH & 0.023 & 0.830 \\
\hline
\end{tabular}

$\mathrm{TSH}=$ Thyroid-stimulating hormone, $\mathrm{T} 3=$ Triiodothyronine, $\mathrm{T} 4$ = Thyroxine, $\mathrm{CD}^{+}=$Cluster of differentiation

Table 4: Correlation between cluster of differentiation cell count and thyroid hormone levels in human immunodeficiency virus-positive individuals subjects highly active anti-retroviral therapy naïve

\begin{tabular}{lcc}
\hline Measured variables & $\boldsymbol{R}$ & $\boldsymbol{P}$ \\
\hline $\mathrm{CD} 4^{+}$and T3 & 0.032 & 0.675 \\
$\mathrm{CD} 4^{+}$and T4 & 0.218 & 0.038 \\
$\mathrm{CD} 4^{+}$and TSH & -0.004 & 0.969 \\
\hline $\mathrm{TSH}=$ Thyroid stimulating hormone, $\mathrm{T} 3=$ Triiodothyronine, $\mathrm{T} 4=$ Thyroxine, \\
$\mathrm{CD} 4^{+}=$Cluster of differentiation
\end{tabular}

Table 5: Correlation between cluster of differentiation cell count and thyroid hormone levels in human immunodeficiency virus-negative individuals (controls)

\begin{tabular}{lcc}
\hline Measured variables & $\boldsymbol{R}$ & $\boldsymbol{P}$ \\
\hline $\mathrm{CD} 4^{+}$and T3 & -0.013 & 0.936 \\
$\mathrm{CD} 4^{+}$and T4 & 0.150 & 0.336 \\
$\mathrm{CD} 4^{+}$and TSH & 0.146 & 0.351 \\
\hline
\end{tabular}

$\mathrm{TSH}=$ Thyroid-stimulating hormone, $\mathrm{T} 3$ = Triiodothyronine, $\mathrm{T} 4$ = Thyroxine, $\mathrm{CD}^{+}=$Cluster of differentiation

65 females and mean age $38.3 \pm 2.3$ years) HIV-1-negative controls. All the HIV-1-positive individuals on HAART were on tenofovir disoproxil fumarate/lamivudine/ efavirenz and lamivudine/nevirapine/zidovudine combination therapy.

Thyroid function abnormalities were seen in 52 HIV-1-positive individuals on HAART and 56 individuals without HAART treatment. The pattern of thyroid hormones abnormalities is similar in both groups [Table 1]. Of the 100 HIV-1-positive individuals on HAART, 10 had subclinical hypothyroid, 42 sick euthyroid, and 48 had normal thyroid hormones levels. Similarly, out of 100 HIV-1-positive individuals without HAART therapy, seven had subclinical hypothyroid, 49 sick euthyroid, and 44 had normal thyroid hormones levels. Table 2 shows the mean levels of measured parameters in HIV-1-positive individuals on HAART and without HAART treatment and controls. The HIV-1-positive individuals had significantly lower $(P<0.001) \mathrm{CD}_{4}{ }^{+}$cell count, TSH $(P<0.05)$, T3 $(P<0.01)$, and T4 $(P<0.001)$ when compared with controls. On the other hand, HIV-1-positive individuals on HAART had significantly higher $(P<0.01) \mathrm{CD}^{+}$cell count and lower $(P<0.05)$ T4 levels than the HAART naïve group.

$\mathrm{CD}^{+}$correlated positively with T4 in HIV-1-positive individuals on HAART $(r=0.26 ; P=0.016)$ and HAART naïve $(r=0.218 ; P=0.038)$. There was no significant correlation between $\mathrm{CD}^{+}$and measured thyroid hormones in the control individuals [Tables 3-5].

\section{Discussion}

This study evaluated thyroid hormone abnormalities 
in HIV-1 positive on HAART and without HAART treatment. There was no significant difference in the frequency of thyroid hormone abnormalities between those on HAART and HAART naïve. However, a significant correlation was observed between $\mathrm{CD} 4^{+}$cell count and T4 in both groups. The observed insignificant difference in the frequency of thyroid dysfunction between HIV-1-positive individuals on HAART and HAART naïve individuals is consistent with a study by Thongam et al. ${ }^{[23]}$ This is however not consistent other study. ${ }^{[3]} \mathrm{Ji}$ et al. ${ }^{[3]}$ observed that thyroid dysfunction was significantly more frequent in the HAART group than the HAART naïve group. The authors suggested that the differences in the frequency of thyroid dysfunction between the two groups may be associated with differences in disease course. Studies have also reported that HAART plays an important role in thyroid function abnormality..$^{[15-17]}$

Sick euthyroid syndrome was the most frequently observed in our study participants, followed by subclinical hypothyroidism. This did not agree with other studies elsewhere. Clinical hypothyroidism was the most common thyroid dysfunction in HIV-infected individuals. ${ }^{[3,24-26]}$ Hoffman et al. ${ }^{[14]}$ reported that the probability of clinical hypothyroidism in HIV-infected individuals was not different from the general population. Some authors associated thyroid disorders with specific antiretroviral drug. It was reported that hypothyroidism was most common in patients who were on protease inhibitors, while hyperthyroidism was common with those on NNRTI, especially efavirenz. ${ }^{[27]}$ It was suggested that HAART may impact on plasma HIV RNA and increase memory and naïve CD4 cells, production of autoantibodies, and immune reconstitution inflammatory syndrome, which acts against the antigens. ${ }^{[28]}$ The hypothyroidism they observed was linked to autoimmunity. This assertion was disputed by Carvalho et al., ${ }^{[29]}$ who failed to observed significant association between the presences of autoantibodies in HIV-infected individuals. Stress accompanied with advanced disease or concomitant morbidities may manifest as sick euthyroid syndrome as a result of cachexia and/or hypothalamic-pituitary deficit. ${ }^{[23]}$

Subclinical hypothyroidism $(17 / 200 ; 8.5 \%)$ was the second most frequently observed thyroid hormone abnormality in this study which was higher than $4 \%$ reported previously. ${ }^{[21]}$ In a study that was conducted to evaluate the frequency of overt and subclinical thyroid abnormalities in 3584 HIV-infected individuals, it was reported that $60(4 \%)$ had subclinical hypothyroidism, $39(2.5 \%)$ had overt hypothyroidism, $8(0.22 \%)$ had overt hyperthyroidism, $5(0.14 \%)$ had subclinical hyperthyroidism, and 263 (17\%) had sick euthyroid syndrome. They concluded that no association existed between HIV infection, its treatment and thyroid dysfunction..$^{[1]}$ A no evidence of uniform pattern of association between thyroid dysfunction and HIV infection was also reported. . $^{[1,30,31]}$

Of the $200 \mathrm{HIV}-1$-positive infected individuals evaluated, $54 \%$ had asymptomatic thyroid hormone abnormalities. In a study elsewhere conducted to evaluate the prevalence of endocrine disturbances in HIV-infected women, thyroid disorders were reported in $15 \%$ of the participants among other endocrine disorders. ${ }^{[32]}$ Even though the pattern of thyroid hormone abnormalities may differ from one geographical location to another, it is clear from this study that it is a common occurrence that may affect the quality of life of HIV-infected individuals. The cause of thyroid dysfunction in HIV-1-infected individuals is however not clear; however, several suggestions have been made. They include concurrent infections, auto-immune diseases, opportunistic infections, and drug reactions. ${ }^{[18,23]}$

A positive association was observed between $\mathrm{T} 4$ and $\mathrm{CD} 4^{+}$cell count in HIV-1-infected individuals, which is an indication that thyroid hormones abnormalities may be associated with disease progression. Thyroid dysfunction was associated with disease progression and severity in previous studies. ${ }^{[27,33]}$ Even though overt thyroid disorder was not observed among the study population, occasional routine check for thyroid hormone abnormalities is suggested in HIV-1-positive individuals, especially in those with low $\mathrm{CD}^{+}$cell count.

\section{Conclusion}

Asymptomatic thyroid hormone abnormalities are common in HIV-infected individuals. Sick euthyroid syndrome and subclinical hypothyroidism were the abnormalities observed in this study. The frequency in which these abnormalities occurred was independent of whether the individuals were on HAART or without HAART treatment.

\section{Limitation of the study}

The inability to evaluate free T3, T4, and thyroid-binding globulin may be regarded as a limitation.

\section{Financial support and sponsorship}

Nil.

\section{Conflicts of interest}

There are no conflicts of interest.

\section{References}

1. Wang JJ, Zhou JJ, Yuan XL, Li CY, Sheng H, Su B, et al. Hyperthyroidism caused by acquired immune deficiency 
syndrome. Eur Rev Med Pharmacol Sci 2014;18:875-9.

2. National Agency for the Control of AIDS (NACA). Women, Girls and HIV in Nigeria. Available from: http:/ / naca.gov.ng/index2. php.com. [Last assessed on 2015 Jun 12].

3. Ji S, Jin C, Höxtermann S, Fuchs W, Xie T, Lu X, et al. Prevalence and influencing factors of thyroid dysfunction in HIV-infected patients. Biomed Res Int 2016;2016:3874257.

4. Bongiovanni M, Adorni F, Casana M, Tordato F, Tincati C, Cicconi $\mathrm{P}$, et al. Subclinical hypothyroidism in HIV-infected subjects. J Antimicrob Chemother 2006;58:1086-9.

5. Madeddu G, Spanu A, Chessa F, Calia GM, Lovigu C, Solinas P, et al. Thyroid function in human immunodeficiency virus patients treated with highly active antiretroviral therapy (HAART): A longitudinal study. Clin Endocrinol (Oxf) 2006;64:375-83.

6. Hoffmann CJ, Brown TT. Thyroid function abnormalities in HIV-infected patients. Clin Infect Dis 2007;45:488-94.

7. Mylonakis E, Koutkia P, Grinspoon S. Diagnosis and treatment of androgen deficiency in human immunodeficiency virus-infected men and women. Clin Infect Dis 2001;33:857-64.

8. Tang WW, Kaptein EM. Thyroid hormone levels in the acquired immunodeficiency syndrome (AIDS) or AIDS-related complex. West J Med 1989;151:627-31.

9. Silva GA, Andrade MC, Sugui Dde A, Nunes RF, Pinto JF, Eyer Silva WA, et al. Association between antiretrovirals and thyroid diseases: A cross-sectional study. Arch Endocrinol Metab 2015;59:116-22.

10. Noureldeen AF, Qusti SY, Khoja GM. Thyroid function in newly diagnosed HIV-infected patients. Toxicol Ind Health 2014;30:919-25.

11. Dobs AS, Dempsey MA, Ladenson PW, Polk BF. Endocrine disorders in men infected with human immunodeficiency virus. Am J Med 1988;84:611-6.

12. Sellmeyer DE, Grunfeld C. Endocrine and metabolic disturbances in human immunodeficiency virus infection and the acquired immune deficiency syndrome. Endocr Rev 1996;17:518-32.

13. Olivieri A, Sorcini M, Battisti P, Fazzini C, Gilardi E, Sun Y, et al. Thyroid hypofunction related with the progression of human immunodeficiency virus infection. J Endocrinol Invest 1993;16:407-13.

14. Grappin M, Piroth L, Verges B, Sgro C, Mack G, Buisson M, et al. Increased prevalence of subclinical hypothyroidism in HIV patients treated with highly active antiretroviral therapy. AIDS 2000;14:1070-2.

15. Calza L, Manfredi R, Chiodo F. Subclinical hypothyroidism in HIV-infected patients receiving highly active antiretroviral therapy. J Acquir Immune Defic Syndr 2002;31:361-3.

16. Beltran S, Lescure FX, El Esper I, Schmit JL, Desailloud R. Subclinical hypothyroidism in HIV-infected patients is not an autoimmune disease. Horm Res 2006;66:21-6.

17. Collazos J, Ibarra S, Mayo J. Thyroid hormones in HIV-infected patients in the highly active antiretroviral therapy era: Evidence of an interrelation between the thyroid axis and the immune system. AIDS 2003;17:763-5.

18. Saravanan P, Dayan CM. Assessment of thyroid function disease: Thyroid autoantibodies. Endocrinol Metab Clin 2001;30:315-37.

19. Chen F, Day SL, Metcalfe RA, Sethi G, Kapembwa MS, Brook MG, et al. Characteristics of autoimmune thyroid disease occurring as a late complication of immune reconstitution in patients with advanced human immunodeficiency virus (HIV) disease. Medicine (Baltimore) 2005;84:98-106.

20. Parsa AA, Bhangoo A. HIV and thyroid dysfunction. Rev Endocr Metab Disord 2013;14:127-31.

21. Madge S, Smith CJ, Lampe FC, Thomas M, Johnson MA, Youle M, et al. No association between HIV disease and its treatment and thyroid function. HIV Med 2007;8:22-7.

22. Lwange S, Lemeshow S. Sample Size Determination in Health Studies. A Practical Manual. Geneva: World Health Organization; 1991. p. 23-41.

23. Thongam S, Keithelakpam S, Singh TY, Singh RL, Singh AM, Ranabir $S$, et al. Thyroid dysfunction in human immunodeficiency virus-infected children and its correlation with CD4(+) T lymphocyte count. Indian J Endocrinol Metab 2015;19:272-6.

24. Savès M, Raffi F, Capeau J, Rozenbaum W, Ragnaud JM, Perronne C, et al. Factors related to lipodystrophy and metabolic alterations in patients with human immunodeficiency virus infection receiving highly active antiretroviral therapy. Clin Infect Dis 2002;34:1396-405.

25. Beltran S, Lescure FX, Desailloud R, Douadi Y, Smail A, El Esper I, et al. Increased prevalence of hypothyroidism among human immunodeficiency virus-infected patients: A need for screening. Clin Infect Dis 2003;37:579-83.

26. Chiarelli F, Galli L, Verrotti A, di Ricco L, Vierucci A, de Martino M, et al. Thyroid function in children with perinatal human immunodeficiency virus type 1 infection. Thyroid 2000;10:499-505.

27. Nelson M, Powles T, Zeitlin A, Sen P, Scourfield A, Bower M, et al. Thyroid dysfunction and relationship to antiretroviral therapy in HIV-positive individuals in the HAART era. J Acquir Immune Defic Syndr 2009;50:113-4.

28. Sharma N, Sharma LK, Dutta D, Gadpayle AK, Anand A, Gaurav K, et al. Prevalence and predictors of thyroid dysfunction in patients with HIV infection and acquired immunodeficiency syndrome: An Indian perspective. J Thyroid Res 2015;2015:517173.

29. Carvalho LG, Teixeira Pde F, Panico AL, Cohen MV, Pinheiro MF, Barroso PF, et al. Evaluation of thyroid function and autoimmunity in HIV-infected women. Arq Bras Endocrinol Metabol 2014;58:86.

30. Dobs AS, Dempsey MA, Ladenson PW, Polk BF. Endocrine disorders in men infected with human immunodeficiency virus. Am J Med 1988;84(3 Pt 2):611-6.

31. Bonfanti P, Valsecchi L, Parazzini F, Carradori S, Pusterla L, Fortuna $\mathrm{P}$, et al. Incidence of adverse reactions in HIV patients treated with protease inhibitors: A cohort study. Coordinamento Italiano Studio Allergia e Infezione da HIV (CISAI) Group. J Acquir Immune Defic Syndr 2000;23:236-45.

32. Sokalski KM, Chu J, Mai AY, Qiu AQ, Albert AY, Zanet DL, et al. Endocrine abnormalities in HIV - infected women are associated with peak viral load-the children and women: Antiretrovirals and markers of aging (CARMA) cohort. Clin Endocrinol (Oxf) 2016;84:452-62.

33. Hirschfeld S, Laue L, Cutler GB Jr, Pizzo PA. Thyroid abnormalities in children infected with human immunodeficiency virus. J Pediatr 1996;128:70-4. 